Iran Journal of Nursing (IJN)

Vol 34, No. 132, Oct 2021: 89- 101

\title{
Evaluation of The effect of Self-Care Education on Quality of Life in People with Spinal Cord Injury
}

\author{
Fariba Nasiri Ziba ${ }^{1}$, Faeze Shafie Bafti ${ }^{2}$, Naima Seyedfatemi ${ }^{3}$, Taher Doroudi ${ }^{4}$, \\ Hamid Haghani ${ }^{5}$
}

\begin{abstract}
Background \& Aims: Spinal cord injury is usually debilitating and has many negative effects on the quality of life of people due to secondary complications. Therefore, improving the quality of life of people with spinal cord injury is one of the main priorities in the nursing profession. Also, educating self-care behaviors and obtaining information from nurses can be helpful for people with this problem. Self-care is also the most important form of primary care for chronic diseases in the health sector. The aim of this study was to determine the effect of self-care education on the quality of life of people with spinal cord injury referred to Khatam OlAnbia Hospital in Tehran.

Materials \& Methods: The present study was a quasi-experimental study with a control group. 84 patients with spinal cord injury referred to Khatam Ol-Anbia Hospital in Tehran in the first 6 months of 2020 were selected through systematic random sampling and divided in two groups; an intervention group and a control group.

The questionnaire used in this study is an abbreviated form of WHO Quality of Life Assessment Group. WHOQOL-BREF Introduction is a 26-item questionnaire that measures a person's overall quality of life. This questionnaire has four subscales and an overall score. These subscales include: physical health, mental health, social relationships, environmental health, and an overall score. The reliability of Quality of Life questionnaire was achieved through Cronbach's alpha which was equal to $\alpha=0.79$ and internal correlation coefficient was calculated for relative reliability which was equal to 0.85 . After coordination with the officials of Khatam OlAnbia Hospital in Tehran, the researcher referred to the spinal cord injury wards and after introducing himself, explaining the nature and objective of the research, and the procedures to conduct the study to the ward staff, the patients, and their companions, received informed consent from the patients.

The pre-test was performed for both groups and before the intervention, the questionnaires of demographic characteristics and WHO Quality of Life were completed by patients admitted to the spinal cord injury wards. Then, the intervention group was formed in the social network entitled "Self-care and spinal cord injuries" and in addition to the usual training, 30-session self-care training was conducted every day for 30 minutes which lasted a month. The training included description of the disease, complications of the disease, types of pharmacological and non-pharmacological treatments for disease control, self-care and its importance in rehabilitation, how to follow a proper diet, how to follow the prescribed medication and daily activities, exercise and physical activity, counseling and talking with friends, family and non- family support, the skills of how to change the position, transfer, increase performance and independence of patients with spinal cord injury.

In this study, 42 patients participated in each group, and 4 patients in the intervention group and 2 in the control group were excluded from the study for reasons such as cancellation of cooperation, not completing the questionnaire in pre-test or post-test stages, not studying the material submitted for more than three sessions (according to the feedback, the daily review of message information, analyzing Read or Delivered option in the

1. Department of Medical- Surgical Nursing, School of Nursing and Midwifery, Iran University of Medical Sciences, Tehran, Iran

2. Department of Medical- Surgical Nursing, School of Nursing and Midwifery, Iran University of Medical Sciences, Tehran, Iran (Corresponding Author) Tel: 09136782876 Email: shafiebafti.f@iums.ac.ir

3. Department of Psychiatric Nursing, Nursing Care Research Center, School of Nursing and Midwifery, Iran University of Medical Sciences, Tehran, Iran

4. Department of Psychology, Shefa Neuroscience Research Center, Khatam- Ol-Anbia Hospital, Tehran, Iran

5. Department of Biostatistics, School of Health, Iran University of Medical Sciences, Tehran, Iran
\end{abstract}


social network), and finally a total of 38 patients comprised the intervention group and 40 patients the control group.

At first, the patients were asked not to post irrelevant material and to express their views if they had any questions or concerns about the training provided. Also, only routine trainings were performed for the control group. To perform the post-test, one month after the end of the educational intervention, the tools were completed again by the two groups. The post-test was performed for the patients who returned to the hospital and the spinal cord injury wards on time, but for other patients, the questionnaires were sent privately to the social network and were completed remotely. After the posttest, the educational booklet was given to the control group. In this research, educational content was prepared by referring to the available library resources and with the guidance of supervisors and consultants.

The validity of the educational content was assessed qualitatively by a survey of 3 faculty members. After collecting data, the results were analyzed through descriptive and inferential tests such as Fisher's exact test, Chi-square, independent t-test, and paired t-test in SPSS 16.

Results: The results indicated no difference between the two groups in terms of distribution of underlying variables. Comparison of quality of life showed that the quality of life in patients with spinal cord lesions was not statistically significant before and after the intervention $(\mathrm{P}>0.05)$ and also the quality of life in the two groups was improved after the intervention and a statistically significant difference was observed $(\mathrm{P}<0.001)$. Regarding the changes in quality of life score, the mean quality of life of patients with spinal cord injury before the intervention was $13.10 \pm 14.57$ in the intervention group and $13.43 \pm 13.97$ in the control group. One week after the intervention, the mean quality of life of patients with spinal cord injury was $22.38 \pm 13.98$ in the intervention group and $15 \pm 14.48$ in the control group.

Conclusion: The results indicate that self-care program training is effective in improving the quality of life of patients with spinal cord injury. According to the researcher, several factors affect the results, including the nature of the disease, involvement of all body systems, and difficult conditions (lack of definitive treatment, dependence on nurses and informal caregivers) that make it difficult to control the disease. On the other hand, environmental conditions and economic situation, as well as lack of easy access to some drugs may have been involved in assessing the quality of life of these patients. According to the results, the method used in the present study can be suggested to nurses as a simple, non-invasive, low-cost, and effective method in improving the quality of life of patients with spinal cord injury.

Keywords: Education, Self-Care, Quality of Life, Spinal Cord Injuries, Patients

\section{Conflict of Interest: No}

How to Cite: Nasiri Ziba F, Shafie Bafti F, Seyedfatemi N, Doroudi T, Haghani H. Evaluation of The effect of Self-Care Education on Quality of Life in People with Spinal Cord Injury. Iran Journal of Nursing. 2021; 34(132):89-101.

Received: 19 Jul 2021

Accepted: 18 Oct 2021 


\title{
تأثير آموزش برنامهى خودمراقبتى بر كيفيت زندكى افراد با ضايعات نخاعى
}

\author{
فريبا نصيرى زيبا'، فائزه شفيعى بافتى '، نعيمه سيدفاطمى '، طاهر درودى
}

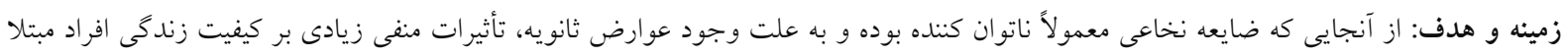

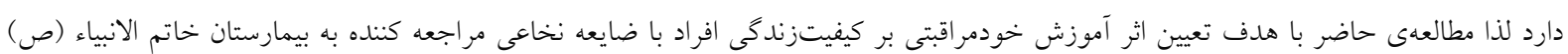
شهر تهران انجام شد.

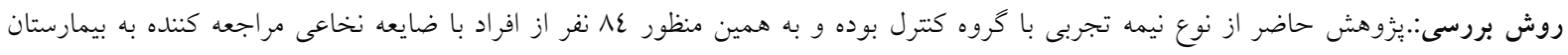

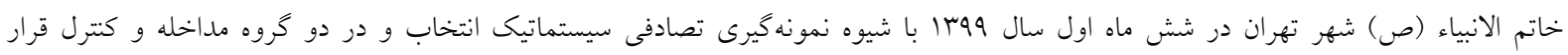

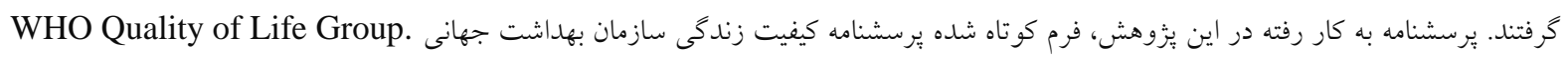
(WHOQOL-BREF Introduction) توصيفى و استنباطى مورد تجزيه و تحليل قرار كرفنتن.

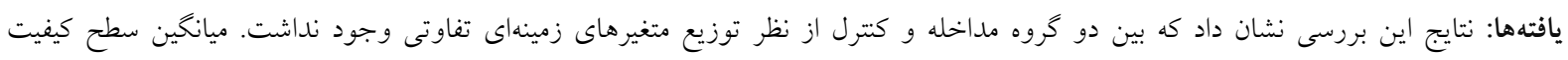

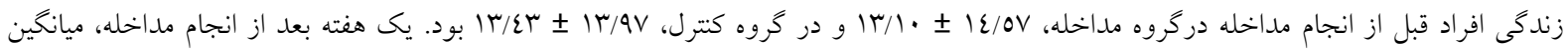

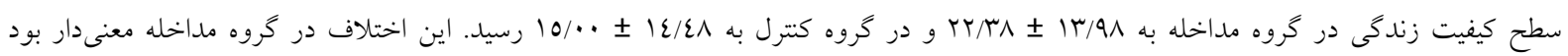
$(\mathrm{p}<\cdot / \cdot \cdot 1)$

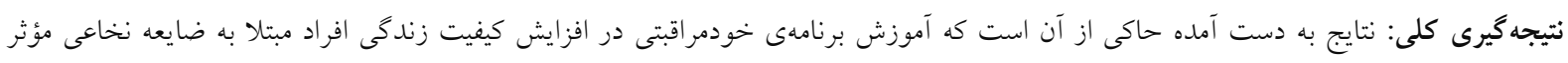

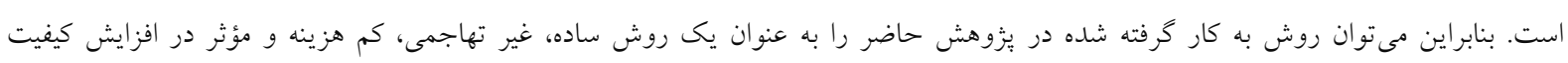

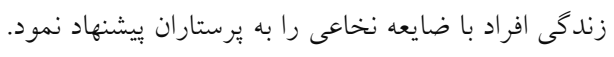

كليد وازهها: آموزش، خودمراقبتى، كيفيت زندگى، ضايعه نخاعى، افراد

$$
\text { تاريخ دريافت: تارض منافع: ندارد }
$$

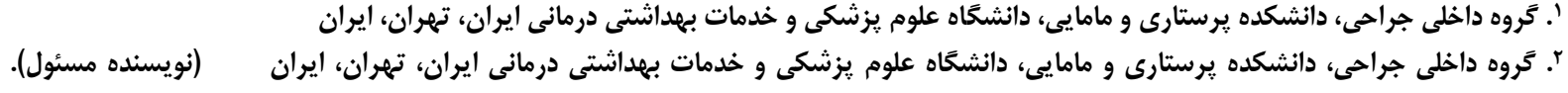

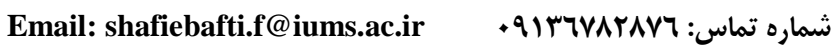

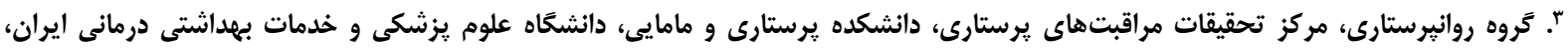
تهران، ايران

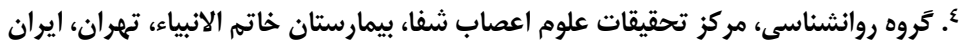

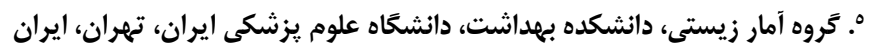


كرفتار افسردگى و نا اميدى مىشوند كه بر كيفيت زندكى اين افراد تأثير منفى مى كذارد (9)

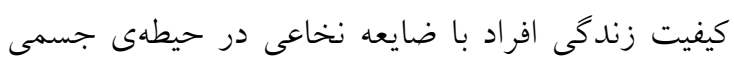

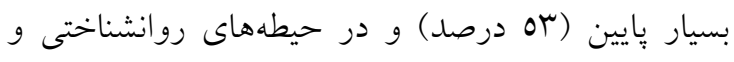

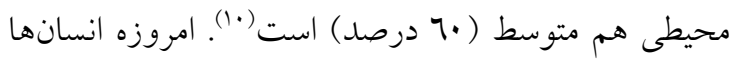
نه تنها تمايل به طول عمر بيشترى دارند، بلكه خواستار

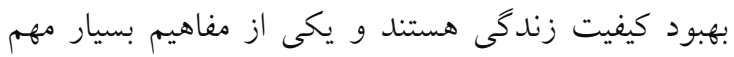
در زندكى افراد، كيفيت زندكى است. مقوله كيفيت زندكى به اين دليل اهميت دارد كه مىتواند در صورت ناديده كرفتن منجر به ناميدى، نداشتن انخيزه براى هركونه تلاش و كاهش فعاليتهاى اجتماعى، اقتصادى،

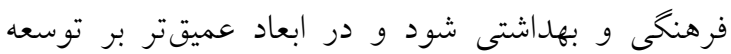
اجتماعى و اقتصادى يك كشور تأثير بخذارد. به عبارت ديخر با ارتقاء كيفيت زندگى در جهت ارتقاء سلامتى گام

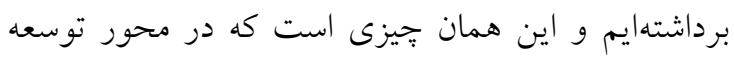
قرار دارد و هدف نهايى تمام دولتها مىباشد (•(1). كيفيت

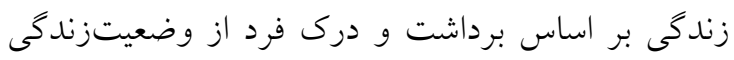

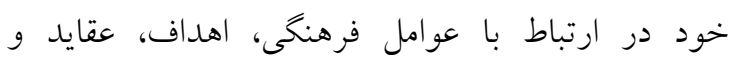

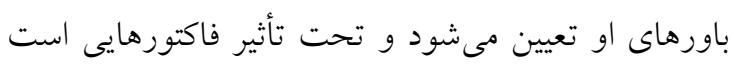

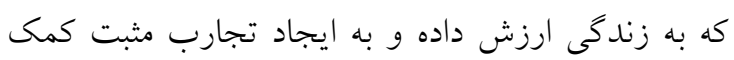

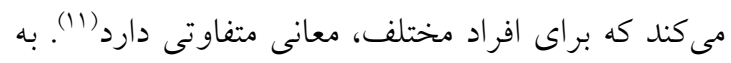

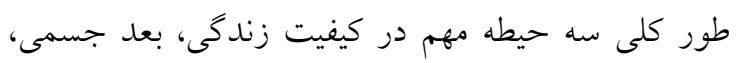

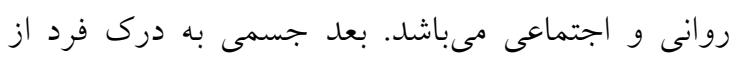

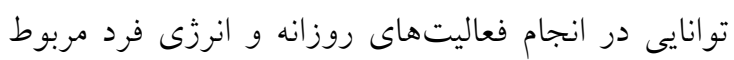

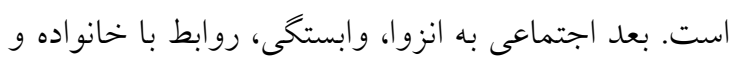

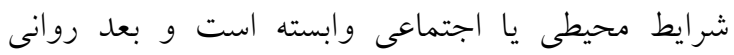

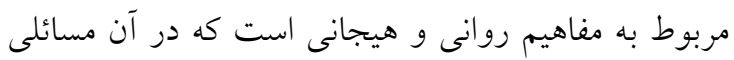
جون افسردگى، ترس، خشم، سلامت، خوشى و اضطراب مطرح مى باشند (Iا). بيشتر تحقيقات حاكى از اين است كه

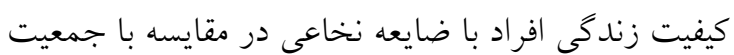
عادى، پايين تر است (r). اخيراً نقش و مسئوليت فرد در فرآيند مراقبت از خود است

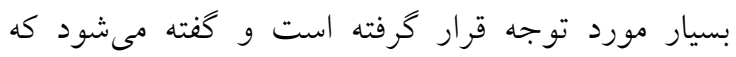
بهترين نتايج مراقبت بهداشتى درمانى زمانى حاصل فردئ
مقلدمه ناتوانى و نقص عضو يديدهاى است كه از ديرباز همراه

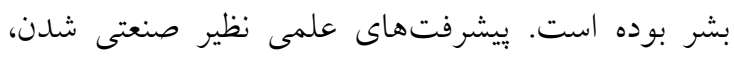
شهرنشينى و رشد فناورىهاى علمى شرايط ايجاد

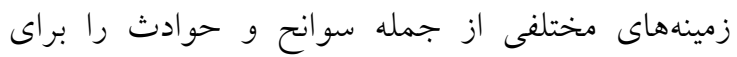

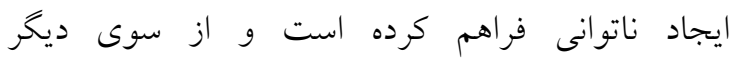

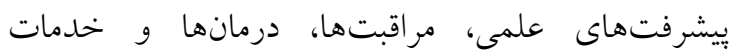
توانبخشى زمينهى حفظ و بقاى بيشتر افراد ناتوان در درى

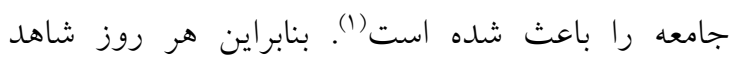
حضور افراد مبتلا به ناتوانى در جوامع بيشتر مىشود كه

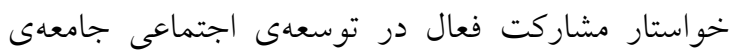
خويش مىباشند (r).

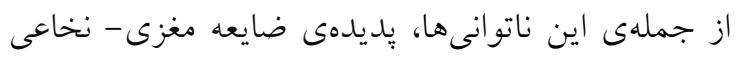
است كه امروزه از رشد قابل ملاحظهاى در بين انواع ناتوانى ها برخوردار مى باشد. تجند وجهى بودن وضعيت

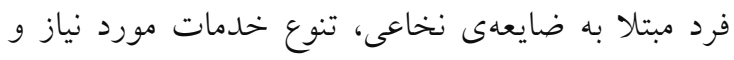

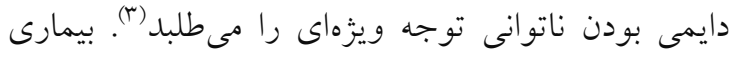

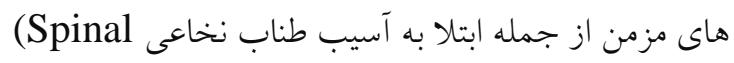
Cord Injury)

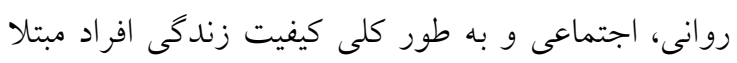

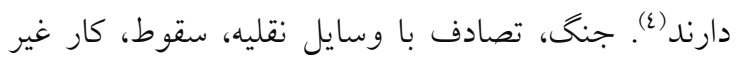

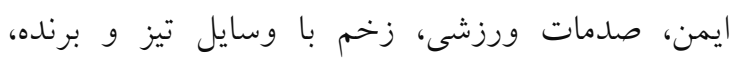

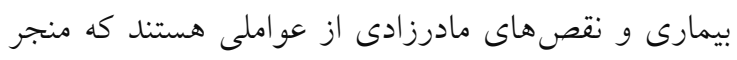
به ايجاد به ضايعه نخاعى مىشوند (0.7). متوسط هآ مآمار

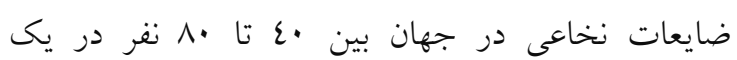

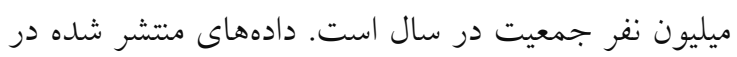

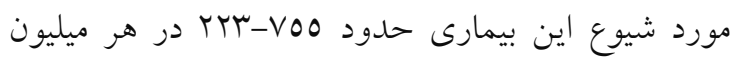

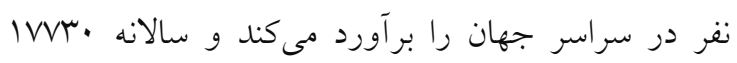
نفر به اين بيمارى مبتلا مىشوند (v) ولى اين آمار در ايران

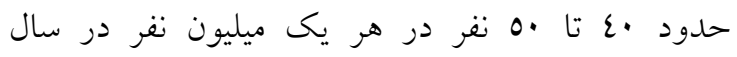

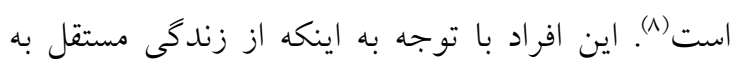

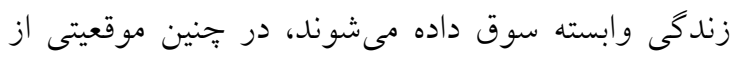
شناسايى و تحقق معنايى با ارزش در زندكى بازمانده و 
آشنايى يرستاران به تمام ابعاد زندكى و درمانى مددجويان

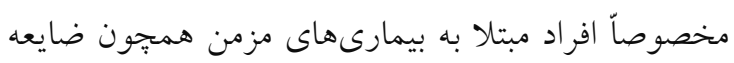

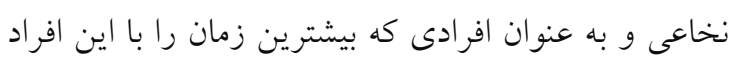

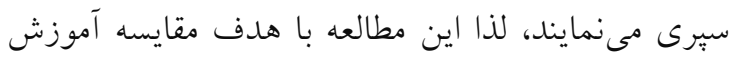
خودمراقبتى بر كيفيت زندگى افراد با ضايعه نتخاعى انجام كرديد.

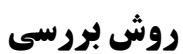

مطالعه حاضر يكى مطالعهى نيمه تجربى با گروه كنترل

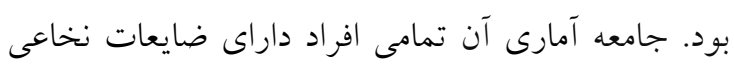

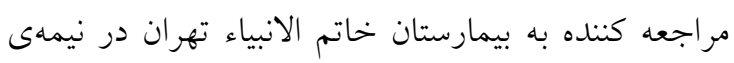

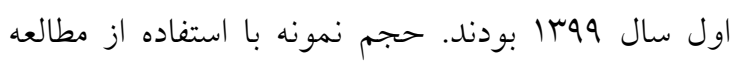

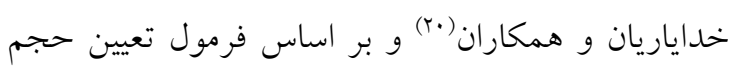

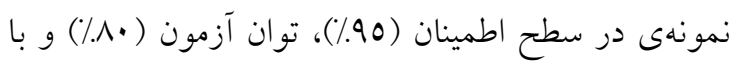

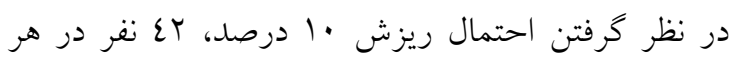

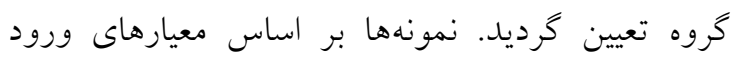

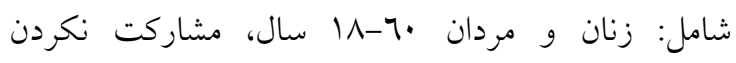

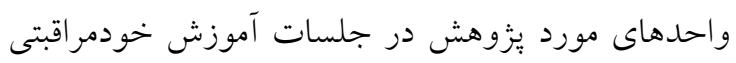

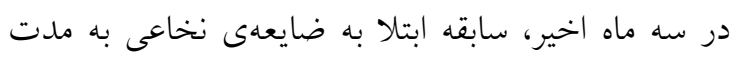

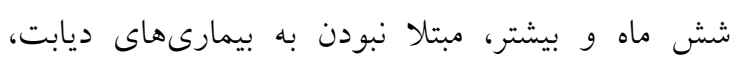

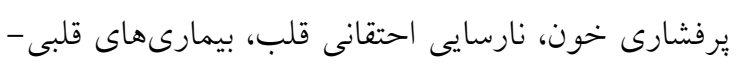

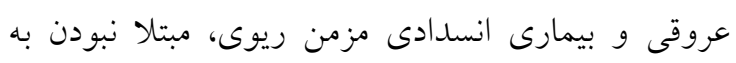

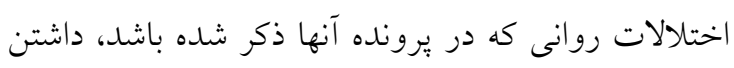

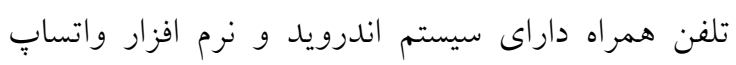

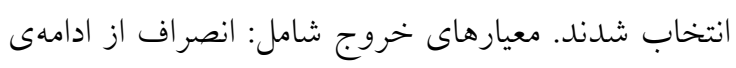
همكارى، تكميل نكردن يرسشنامه در هر يك از مراحل

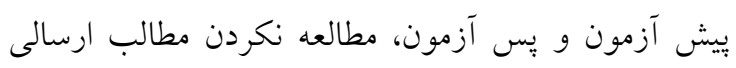

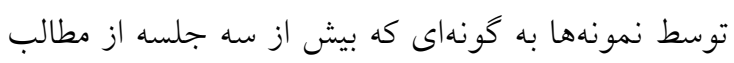

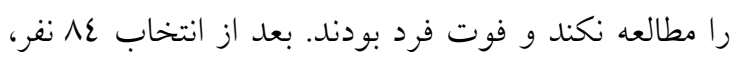

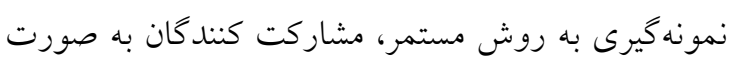

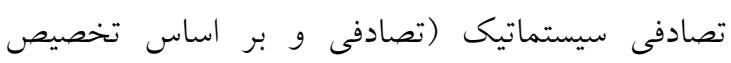

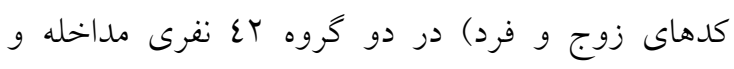

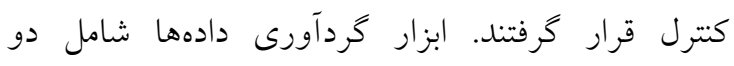

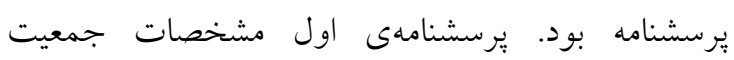

مىشود كه افراد به طور فعال در مراقبت از خود دركير

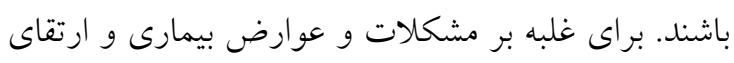

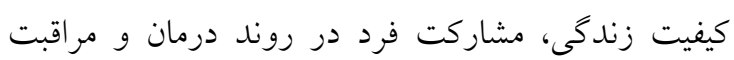

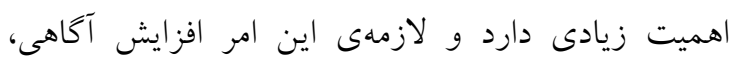

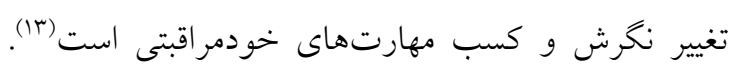

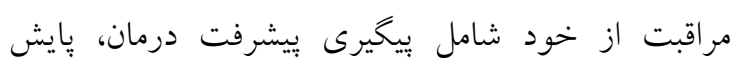

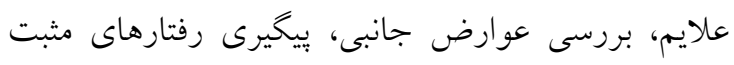

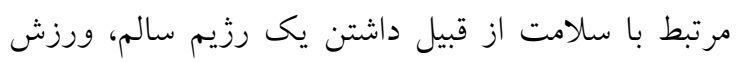

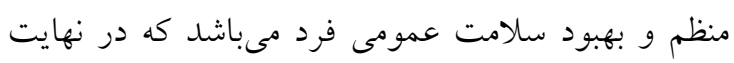

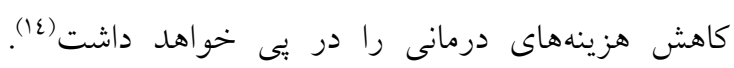

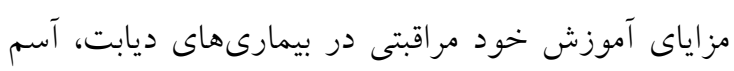
و ساير بيمارىهاى مزمن نيز به طور معنى دارى، به اثبات

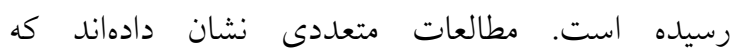

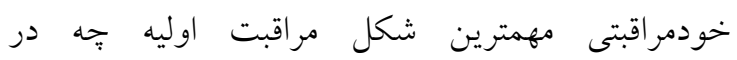
كشورهاى توسعه يافته و يا در كشورهاى در حال توسعه تُونه

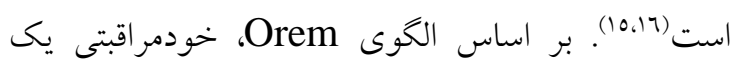

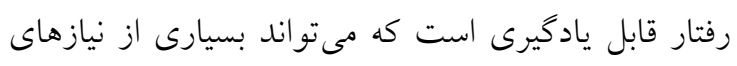

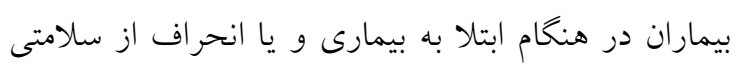

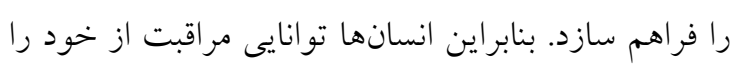

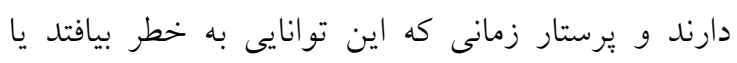

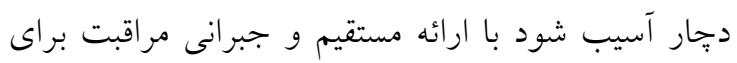

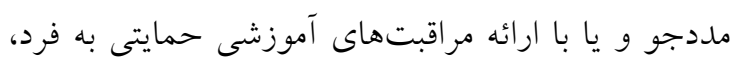

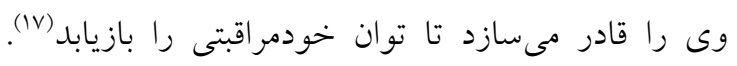

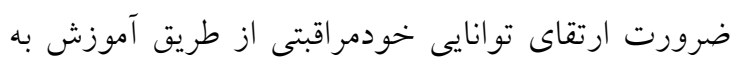

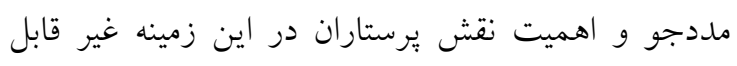

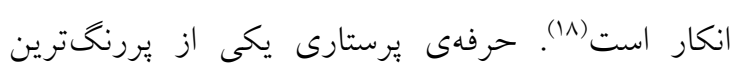

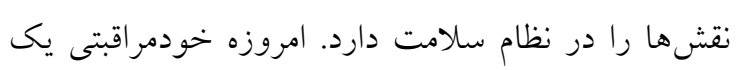

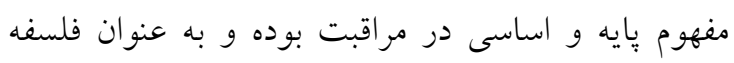
اصلى در يرستارى مىباشد كه اين حرفه را از ساير رشته ونه

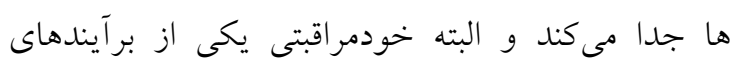

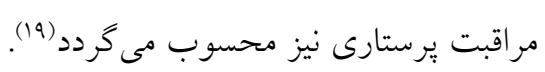
با توجه به اهميت نقش مددجو در فرآيند مراقبت از خود فئرد

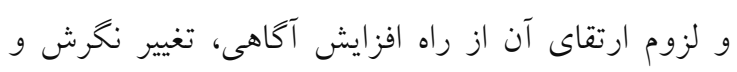

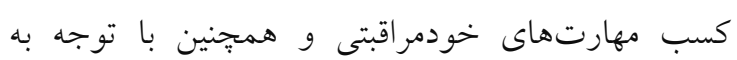


همكاران در سال

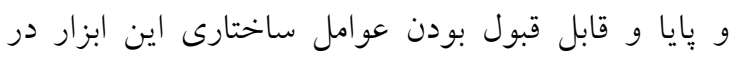

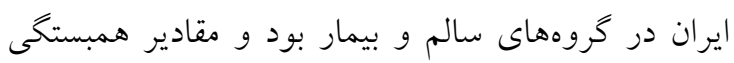
درون خوشهاى و آلفاى كرونباخ آن در تمامى حيطه دها

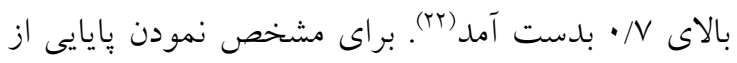

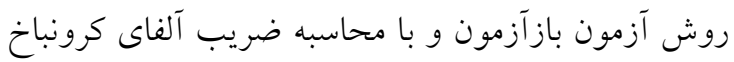

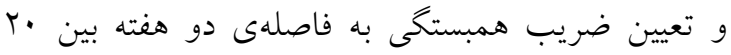

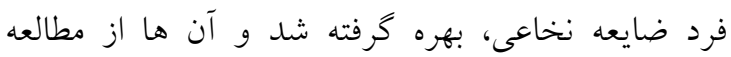

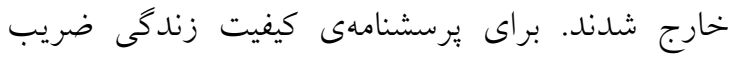

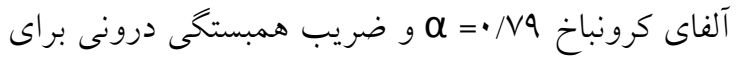

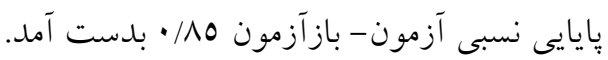

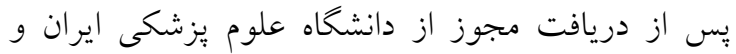
دريافت كد اخلاق از كميتهى اخلاق دانشگاه علوم يزشكى ايران (IR.IUMS.REC.1398.1218) و محقق ضمن معرفى خود، اهداف ثيزوهش را براى نمونه ها بيان نموده و يادآور شد كه شركت در مطالعه كاملاً

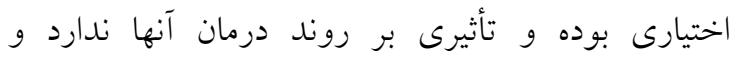

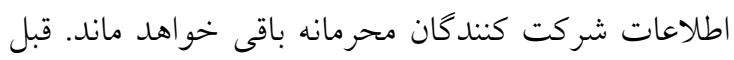

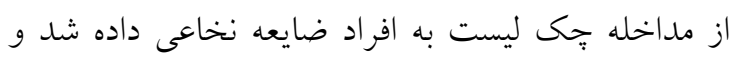

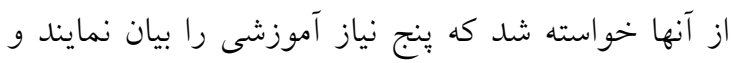
سعى شد اين موارد در مطالب آموزشى كنجانده شوند.

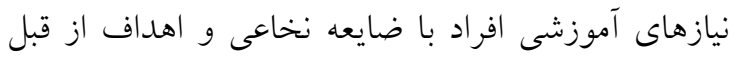

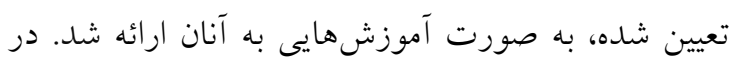

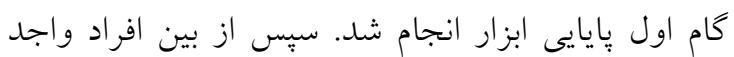

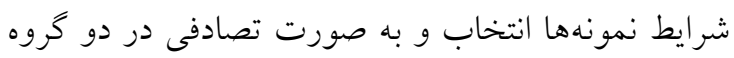

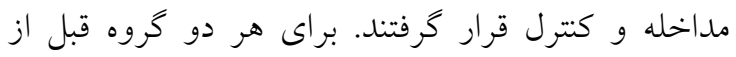

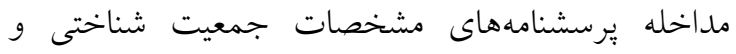
كيفيت زندگى سازمان بهداشت جهانى در بخشهاى بسترى افراد مبتلا به ضايعه نخاعى تكميل شد. سبس يك لئ

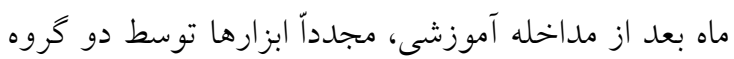

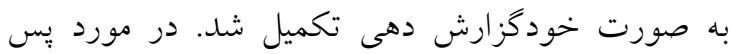
آزمون براى افرادى كه در موعد مقرر مجدداّ به بيمارستان

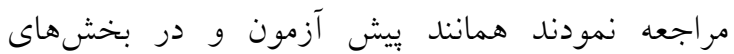
بسترى افراد مبتلا به ضايعه نخاعى تكميل شد اما براى لئل
شناختى واحدهاى مورد يزوهش شامل سن، جنس، سطح تحصيلات، وضعيت تأهل، شغل، مدت زمات زمان ابتلا به به

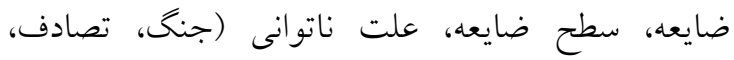
ورزش، سقوط، ساير)، بيمارى زمينهاى، وضعيت بيمهاى،

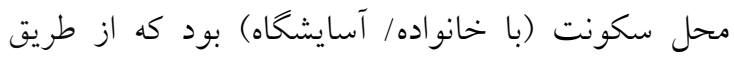

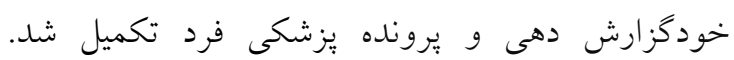

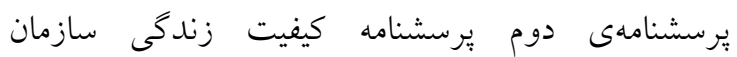
WHO Quality of Life Group. بهداشت جهاني (WHOQOL-BREF Introduction) شامل Tr سؤال است. اين يرسشنامه فرم خلاصه شده يرسشنامه كيفيت زندكى سازمان بهداشت جهانى ..1. سؤال است و داراى ع زيرمقياس و يكى نمره كلى است. زير مقياسها عبارتند از: سلامت جسمى، سلامت روان، روابط اجتماعى، سلامت محيط اطراف و يكى نمره كلى (TI) براى نمره كَارى عبارات يُرسشنامه به هر يكى از گزينهها

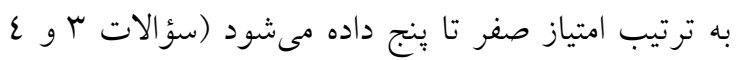

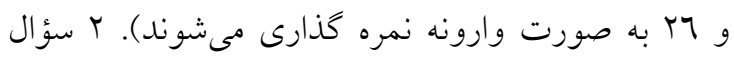

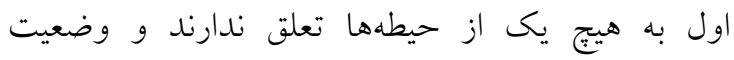

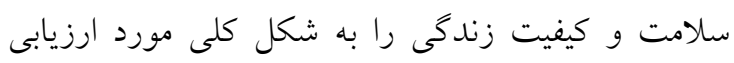

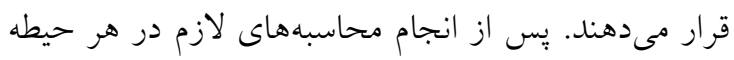

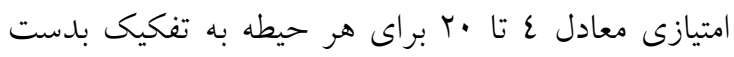

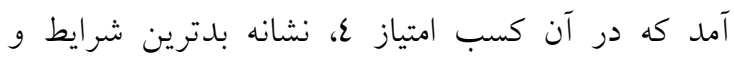
كسب امتياز ·r نشانه بهترين وضعيت حيطه مورد نظر

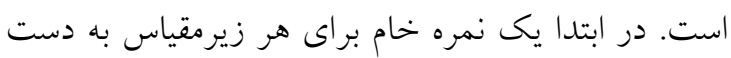

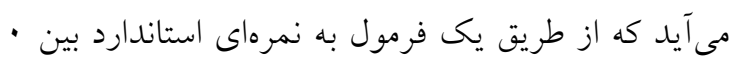
تا ..1 تبديل مىشود. نمره بالاتر نشان دهنده كيفيت

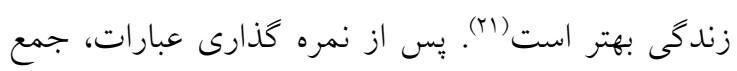

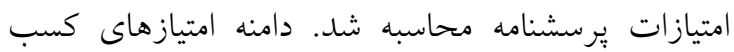
شده در اين ابزار از صفر تا ..1 بوده و امتياز بالاتر بيانخر كيفيت زندگى بهتر مىباشد. بدين ترتيب امتياز ل.' بيانخر بيشترين ميزان كيفيت زندگى و صفر بيانكر حداقل

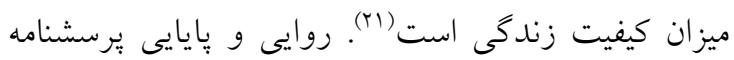
كيفيت زندگى سازمان بهداشت جهانى توسط نجات و 
مداخله بـ كروه كنترل نيز از طريق فضاى مجازى و ارسال فايل ارائه شد. ابتدا با استفاده از روشهاى آمار توصيفى شامل تنظيم جداول توزيع فراوانى دو بعدى و محاسبه شاخص هاى عددى متغيرهاى كمى به تفكيك دو كروه تهيه شد و سيس با استفاده از آزمون كاى اسكوئر، آزمون دقيق فيشر و آزمون تى مستقل، همخن بودن

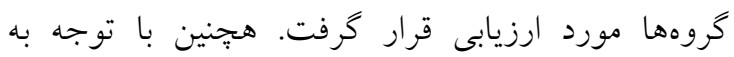
نرمال بودن توزيع دادهها، با استفاده از آزمون تى، كيفيت زندگى در گروه مداخله و كنترل مقايسه شد. در اين مطالعه سطح معنى دارى 0 • • در نظر گرفته شد.

\section{افتهنها}

در كل در هر گروه rأ نقر شركت داشتند كه در گروه مداخله ع نفر به دلايل عدم تمايل همكارى (س نفر) و عدم مطالعه مطالب ارسالى بيش از سه جلسه (1 نفر) و در كروه كنترل r نفر به دلايل عدم تمايل به همكارى (1) نفر) و عدم تكميل يرسشنامه در يس آزمون (ا نفر) از مطالعه خارج شدند (نمودار شماره ()).
بقيه افراد يرسشنامهها از طريق نرم افزار اجتماعى (واتساب) ارسال شد و از راه دور تكميل شدند. در اين

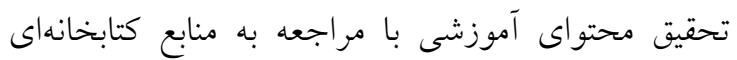
موجود و با راهنمايىهاى اساتيد محترم تهيه شد. روايى محتواى آموزشى، به صورت كيفى با نظرسنجى از سه نفر از اعضاى هيئت علمى مورد ارزيابى قرار گرفت. مداخله به صورت آموزش •ب جلسهاى روزانه از طريق نرم افزار اجتماعى (واتسابٍ) و بهه ملت يكى ماه شامل توصيف بيمارى، عوارض بيمارى، انواع درمان دارويى و غير دارويى براى كنترل بيمـارى، خودمراقبتى و اهميت آن در

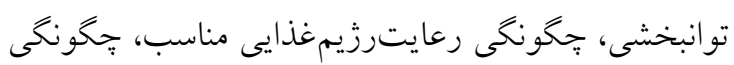
رعايت رزيم دارويى تجويز شده و فعاليت روزمره، ورزش و فعاليت جسمى، مشاوره و صحبت با دوستان، برخوردارى از حمايت خانوادگى و غيرخانوادگى، مهارت هاى جخحونكى تغيير وضعيت، نقل و انتقال، افزايش عملكرد و استقلال و تكرار موضوع جلسات قبل در هر آموزش به صورت يرسش و پِاسخ انجام گرفته و يك ماه بعد از اتمام آموزش، يرسشنامهها تكميل شد. تحليل دادهها از طريق آزمونهاى توصيفى و استنباطى انجام شد. بعد از اتمام مطالعه، تمام محتواى جلسات آموزشى كروه

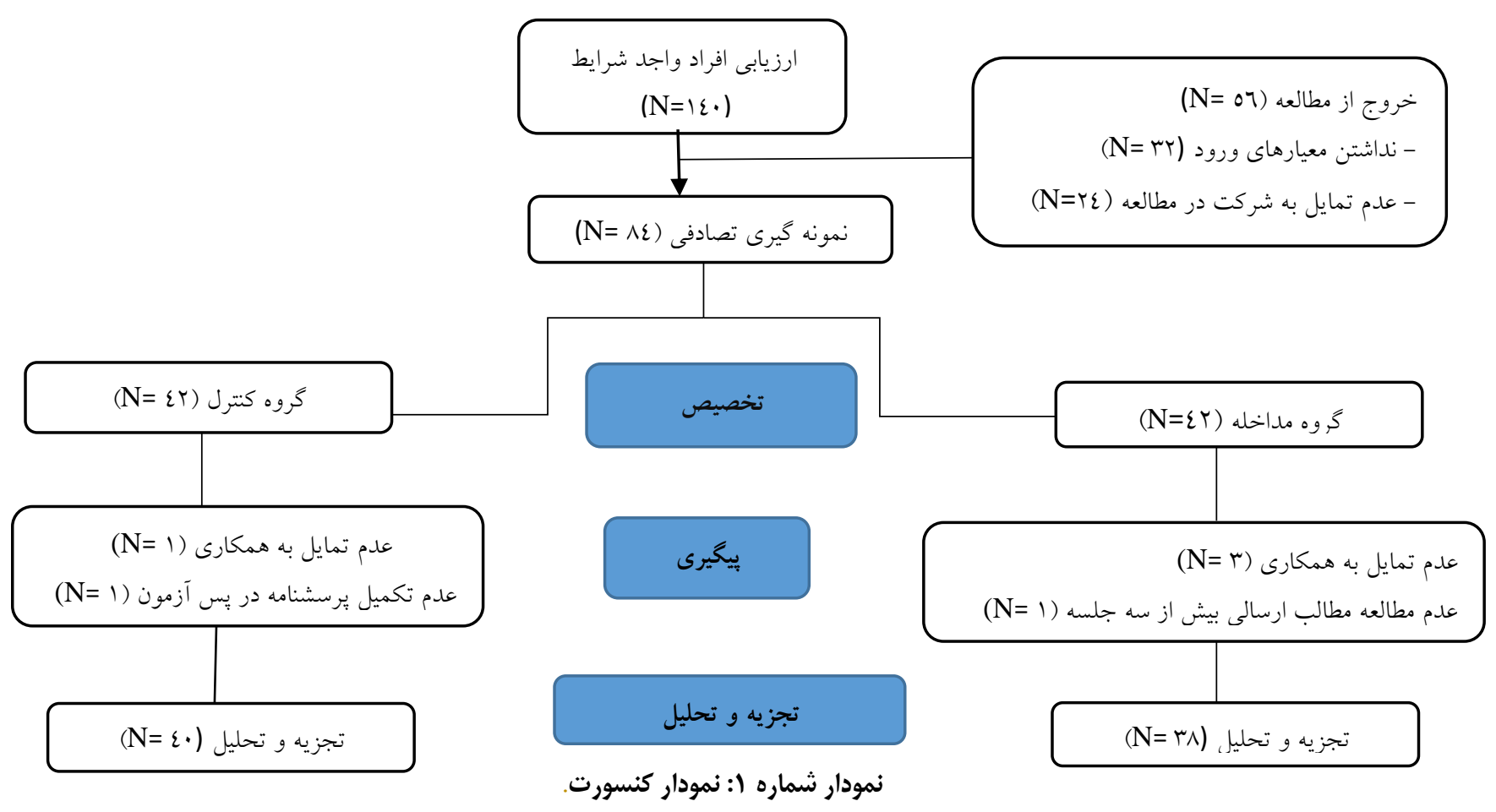




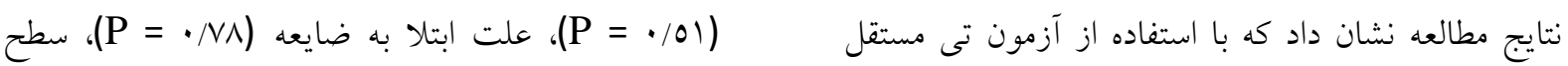

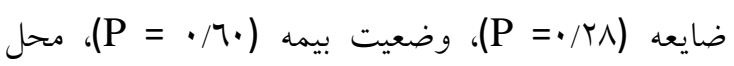

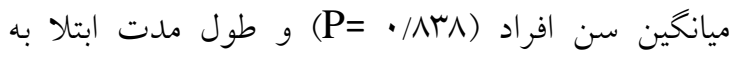
سكونت (P=/\&V) و با استفاده از آزمون كاى اسكوئر،

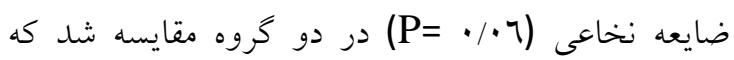

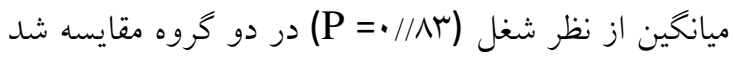

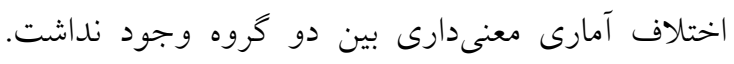
كه تفاوت معنى دارى نداشتند (جدول شماره ()).

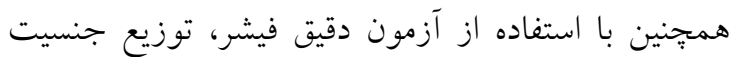

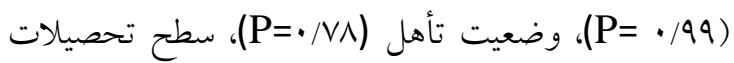

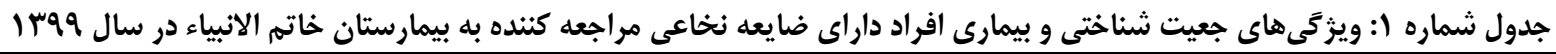

\begin{tabular}{|c|c|c|c|c|c|}
\hline \multicolumn{2}{|r|}{ نتيجه آزمون } & \multirow{2}{*}{ كنترل } & \multirow{2}{*}{ تعداد (درصد } & \multicolumn{2}{|c|}{ كروه } \\
\hline & & & & & متغير \\
\hline \multirow[t]{2}{*}{$\mathrm{t}=\cdot / \mathrm{r}$} & $\mathrm{P}=\cdot / \wedge \uparrow \wedge$ & $(Y Y / 0) 9$ & $(r \mid / T) \mid r$ & 0r-10 سال & سن* \\
\hline & & $(V V / 0) M_{1}$ & (\rceil$/ / \varepsilon) Y\urcorner$ & 1 V-01 سال & \\
\hline \multirow[t]{5}{*}{$\mathrm{t}=1 / 10$} & $\mathrm{P}=\cdot / \cdot 7$ & $(1 \cdot) \varepsilon$ & $(10 / v 9) 7$ & •l-1. r سال & مدت ابتلا به \\
\hline & & $(r \cdot) \mid r$ & . & آr-•r سال & ضايعه نخاعى *** \\
\hline & & $(7 \cdot) r \varepsilon$ & $(O V / Q) Y r$ & بالاى ·r سال & (سال) \\
\hline & $\mathrm{P}=\cdot / \mathrm{N} \wedge$ & $(Y \cdot) \wedge$ & $(Y M / V) 9$ & مجرد/ بيوه/ مطلقه & وضعيت تأهل * \\
\hline & & $(\lambda \cdot)^{\mu r}$ & $(V / / r) Y q$ & متأهل & \\
\hline \multirow[t]{3}{*}{$\mathrm{P}=\cdot / \wedge \uparrow \wedge$} & $\mathrm{X}^{2}=\cdot / \varepsilon \varepsilon$ & $(T V / O) 11$ & $(Y \backslash / I) \wedge$ & بيكار / خانه دار / آزاد & \\
\hline & & (OV/O) & $(7 r / r) Y \varepsilon$ & بازنشسته & شغل *ش**** \\
\hline \multirow{3}{*}{\multicolumn{2}{|c|}{$\mathrm{P}=\cdot / 01$}} & $(10) 7$ & $(10 / 1) 7$ & كارمند & \\
\hline & & (9.) & $(\Lambda \varepsilon / Y) \mu r$ & زير دييلم/ دييلم & سطح تحصيلات* \\
\hline & & $(1 \cdot) \varepsilon$ & $(10 / 1) 7$ & دانشخاهى & \\
\hline \multirow{2}{*}{\multicolumn{2}{|c|}{$\mathrm{P}=\cdot / 99$}} & $(\Lambda V / 0)$ ro & $(\wedge 9 / 0) r \varepsilon$ & مرد & جنسيت \\
\hline & & $(1 Y / 0) 0$ & $(1 \cdot 10) \varepsilon$ & ز ت ان & \\
\hline \multirow{2}{*}{\multicolumn{2}{|c|}{$\mathrm{P}=\cdot / \Gamma \Lambda$}} & (9.) r7 & $(\Lambda 1 / 7) \mu l$ & سينهاى & سطح ضايعه* \\
\hline & & $(1 \cdot) \varepsilon$ & $(\mid \wedge / \varepsilon) \vee$ & 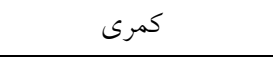 & \\
\hline \multirow{2}{*}{\multicolumn{2}{|c|}{$\mathrm{P}=\cdot / \mathrm{V} \wedge$}} & $(\lambda \cdot) \mu r$ & $(V / / r) r q$ & جنغ & علت ابتلاق* \\
\hline & & $(Y \cdot) \wedge$ & $(Y T / V) 9$ & تصادف/ ورزش/سقوط & \\
\hline \multirow{2}{*}{\multicolumn{2}{|c|}{$\mathrm{P}=\cdot / 2 V$}} & $(9 T / 0) r V$ & س & در منزل و با خانواده & محل سكونت* \\
\hline & & $(V / 0) r$ & $(1 \pi / r) 0$ & آسايشگاه & \\
\hline \multirow{2}{*}{\multicolumn{2}{|c|}{$\mathrm{P}=\cdot / 7$}} & $(90) \mu_{\Lambda}$ & $(9 T / 1)$ ro & دارد & وضعيت بيمها * \\
\hline & & $(0) r$ & $(V / 9)^{r}$ & 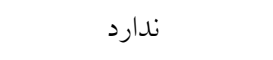 & \\
\hline
\end{tabular}

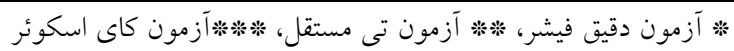

تفاوت آمارى معنىدارى با هم ندارند (0>•P) و همجِنين كيفيت زندكى در دو گروه بعد از انجام مداخله، ارتقاء يافته و تفاوت آمارى معنى دارى مشاهده شد

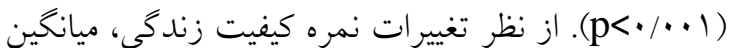

بر اساس هدف مطالعه، ميانخين كيفيت زندگى افراد با ضايعه نخاعى ارزيابى شد كه با مقايسه كيفيت زندگى بين دو گروه قبل و بعد از مدخله، مشخص شد كيفيت زندگى در افراد با ضايعه نخاعى در دو گروه قبل از مداخله، 
كترل به 1/ع/ع| آزمون t مستقل نشان داد كه ميانخين تغييرات نمره كيفيت زندگى در گروه آزمون به طور معنىدارى بيشتر از گروه

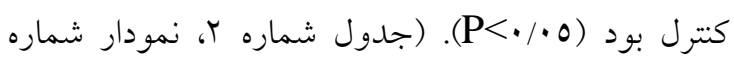

سطح كيفيت زندگى افراد ضايعه نخاعى قبل از انجام

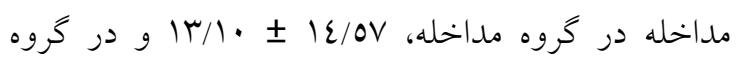
كنترل، از انجام مداخله، ميانخين سطح كيفيت زندكى افراد ضايعه نخاعى در گروه مداخله به

جدول شماره ז: مقايسه كيفيت زندَّى و ابعاد آن در دو كَروه بعد از مداخله در افراد دار الى ضايعه نخاعى مراجعه كننده به بيمارستان خاتم

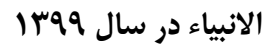

\begin{tabular}{|c|c|c|c|c|}
\hline \multirow{2}{*}{ نتايج آزمون تى مستقل } & 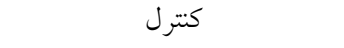 & 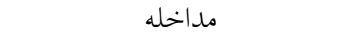 & \multirow[t]{2}{*}{ متغيير } & \\
\hline & انحراف معيار 土 ميانخين & انحر اف معيار土 ميانخين & & \\
\hline $\left.\mathrm{t}=\cdot / \cdot \mathrm{rq}^{\prime} \quad \mathrm{df}=\mathrm{V}\right\urcorner \quad \mathrm{P}=\cdot \mathrm{NV}$ & $11 / / 49 \pm 11 / 09$ & $19 / \cdot v \pm 9 / 1$ & قبل & \\
\hline $\mathrm{t}=r / \mathrm{V}) \quad \mathrm{df}=\mathrm{V} / \quad \mathrm{P}=\cdot \cdots \cdot \cdots$ & $\mid N / \varepsilon \Lambda \pm 11 / \kappa \varepsilon$ & $r \varepsilon / q \cdot \pm q / r V$ & بعد & 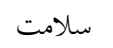 \\
\hline & $\mathrm{t}=-\cdot / r \cdot \mathrm{df}=r q \quad \mathrm{P}<\cdot / \cdot \cdot 1$ & $\mathrm{t}=-\varepsilon / \Lambda \Lambda \quad$ df $\wedge=r \vee \quad \mathrm{P}<\bullet / \cdots)$ & نتيجه آزمون تى زوجى & جسمانى \\
\hline $\mathrm{t}=\{/ \neg) \quad \mathrm{df}=\mathrm{V}\urcorner \quad \mathrm{P}<\cdot / \cdot \cdot 1$ & $\cdot / \bullet \pm Y / V \varepsilon$ & $0 / \Lambda T \pm V / 99$ & تغييرات & \\
\hline $\mathrm{t}=\cdot /{ }^{\prime} \mathrm{df}=\mathrm{V} 7 \quad \mathrm{P}=\cdot / V$ & $|N / r \pm| 1 / \varepsilon \mid$ & $1 N / V O \pm 9 / \cdot r$ & قبل & \\
\hline $\mathrm{t}=r / 07 \quad \mathrm{df}=\mathrm{V} 7 \quad \mathrm{P}=\cdot / \cdot 1 T$ & $|N / O E \pm| Y /||$ & $r \varepsilon / V \Lambda \pm 9 / T r$ & بعد & 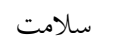 \\
\hline $\mathrm{t}=r / 70 \quad \mathrm{df}=\mathrm{V} 7 \quad \mathrm{P}<\cdot / \cdot \cdot 1$ & $\begin{array}{c}t=-1 / v \cdot d f=r q \quad P<\cdot / \cdot \cdot 1 \\
\cdot / 0 r \pm 1 / 9 r\end{array}$ & $\begin{array}{c}\mathrm{t}=-r / q \Lambda \quad \mathrm{df} \wedge=r V \quad \mathrm{P}<\cdot / \cdot \cdot 1 \\
\tau / r \pm q / r r\end{array}$ & $\begin{array}{c}\text { تيجهه آزمون تى زوجى } \\
\text { تغييرات }\end{array}$ & 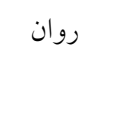 \\
\hline $\mathrm{t}=\cdot / \wedge \quad \mathrm{df}=\vee\urcorner \quad \mathrm{P}=\cdot / \mathrm{N}$. & $r \cdot / \cdots \pm 1 r / 01$ & $r I / r V \pm 10 / 27$ & قبل & \\
\hline $\mathrm{t}=r / r \cdot \quad \mathrm{df}=\vee \tau \quad \mathrm{P}=\cdot / \cdot r \varepsilon$ & $r \cdot / r \cdot \pm I r / V T$ & $r V / 19 \pm 1 r / 90$ & بعد & روابط \\
\hline & $\mathrm{t}=-1 / \cdot \cdot \mathrm{df}=r q \quad \mathrm{P}<\cdot / \cdot \cdot 1$ & $\mathrm{t}=-\varepsilon / \mu r \quad \mathrm{df}=r V \mathrm{P}<\cdot / \cdot \cdot 1$ & نتيجه آزمون تى زوجى & 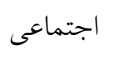 \\
\hline $\mathrm{t}=\varepsilon / \mu \mathrm{r} \quad \mathrm{df}=\mathrm{V}\urcorner \quad \mathrm{P}<\cdot / \cdot \cdot 1$ & $\cdot / r \cdot \pm|/ \mu|$ & $0 / 9 T \pm \Lambda / \varepsilon r$ & 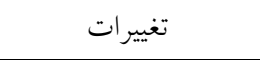 & \\
\hline $\mathrm{t}=\cdot / 0 \mathrm{r} \quad \mathrm{df}=\mathrm{v} 7 \quad \mathrm{P}=\cdot / 09$ & $r \% / 09 \pm 1 \cdot 1 \cdot 1$ & $r \varepsilon / V O \pm q / \cdot 1$ & قبل & \\
\hline $\mathrm{t}=r / \varepsilon \cdot \quad \mathrm{df}=\mathrm{V} 7 \quad \mathrm{P}=\cdot / \cdot 19$ & $r \varepsilon / 1 \varepsilon \pm 1 \cdot / r_{0}$ & $r q / \varepsilon \varepsilon \pm q / 1 V$ & بعد & 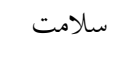 \\
\hline & $\mathrm{t}=-1 / \wedge 7 \quad \mathrm{df}=r q \quad \mathrm{P}<\cdot / \cdot \cdot 1$ & $\mathrm{t}=-\cdot \varepsilon / \cdots \quad \mathrm{df}=r V \quad \mathrm{P}<\cdot / \cdots)$ & نتيجه آزمون تى زوجى & محيط \\
\hline $\mathrm{t}=r / 0 \cdot \mathrm{df}=\mathrm{V}\urcorner \quad \mathrm{P}<\cdot / \cdot \cdot 1$ & $\cdot / 0 \varepsilon \pm 1 / 10$ & $\{/ \nearrow \perp \pm V / r)$ & ت ت تغييرات & \\
\hline $\mathrm{t}=\cdot / 0 \mathrm{r} \quad \mathrm{df}=\mathrm{V} \mathrm{T} \quad \mathrm{P}=\cdot / 7$ & $1 r / \varepsilon r \pm 1 r / 9 V$ & $|r /| \cdot \pm 1 \varepsilon / 0 V$ & قبل & كيفيت \\
\hline $\mathrm{t}=r / r \Lambda \quad \mathrm{df}=V\urcorner \quad \mathrm{P}=\cdot / \cdot r_{0}$ & $10 / \cdots \pm 1 \varepsilon / \varepsilon \wedge$ & $r Y / \mu \Lambda \pm \mid r / 9 \Lambda$ & بعد & 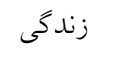 \\
\hline & $t=-\cdot / r v \quad d f=r q \quad P<\cdot / \cdot \cdot 1$ & $\mathrm{t}=-\varepsilon / \mathrm{v} \cdot \quad \mathrm{dff} v \quad \mathrm{P}<\bullet / \cdots)$ & نتيجه آزمون تى زوجى & 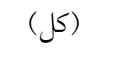 \\
\hline $\mathrm{t} t=\varepsilon / \cdot 1 \quad \mathrm{df}=\mathrm{v}\urcorner \quad \mathrm{P}<\cdot / \cdot \cdot 1$ & $0 /{ }^{\prime} \Lambda \pm \cdot /{ }_{1}$ & $Q / \Sigma V \pm V / r r$ & تغييرات & \\
\hline
\end{tabular}

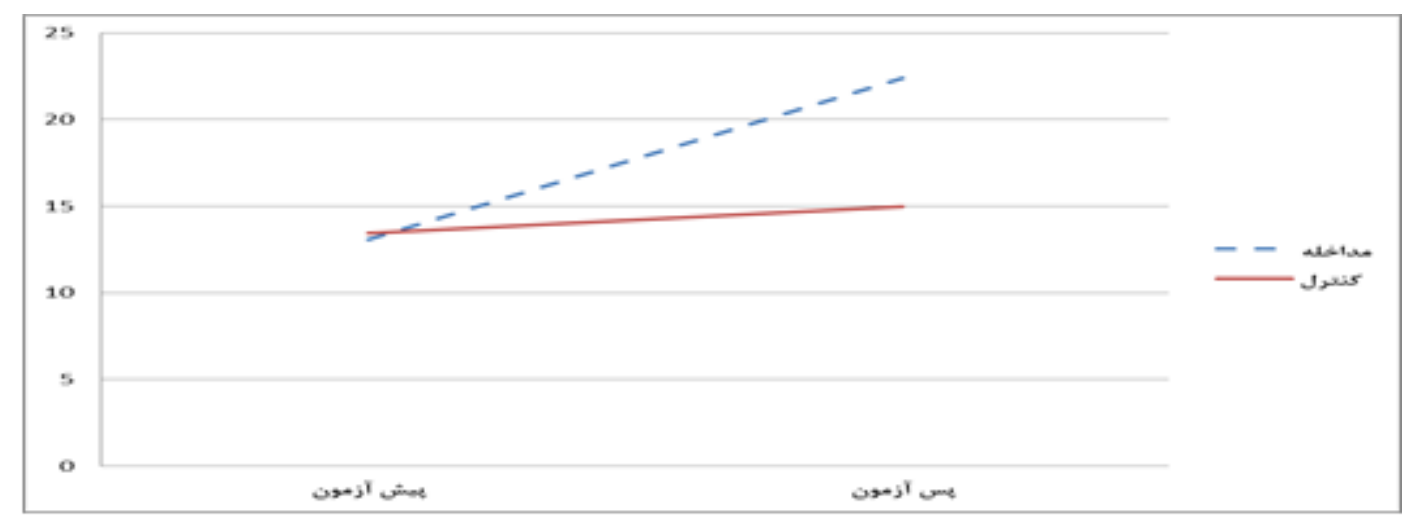

نمودار شماره ז: روند تغيير ميانَّين كيفيت زندَّى افراد داراى ضايعه نخاعى به تفكيك تَروههاى مداخله و كنترل 
ايران- عراق و عوامل مرتبط با آن انجام دادند. اين مطالعه

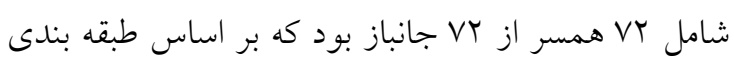

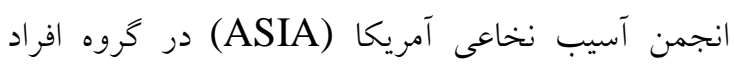
داراى ضايعه نخاعى طبقه بندى شدند. كيفيت زندئ أندى

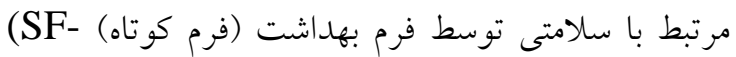

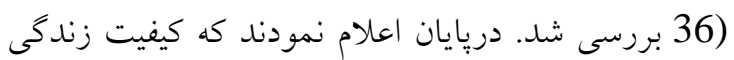
واحدهاى مورد مطالعه در بِايينترين حد خود قرار

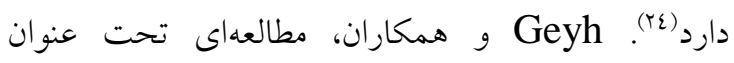
كيفيت زندگى بعد از ابتلا به آسيب نخاعى (يكى مطالعه

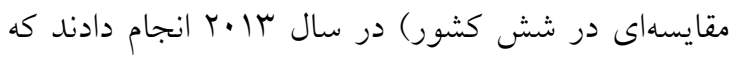
دادههاى rع فرد مبتلا به ضايعه نخاعى از استراليا،

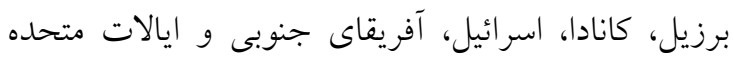
تجزيه و تحليل شد. ميانخين كيفيت زندكى باعب نفر از افراد با ضايعه نخاعى از كشورهاى استراليا، برزيل، كانادا،

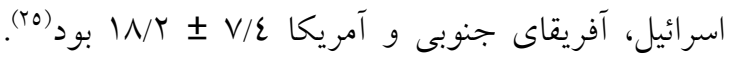
عوامل متعددى از نظر محقق در نتايج بدست آمده دخيل

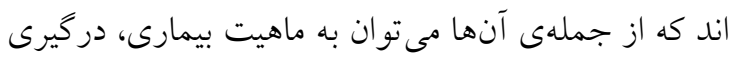
كل سيستمهاى بدن و شرايط سختى كه كنترل بيمارى را

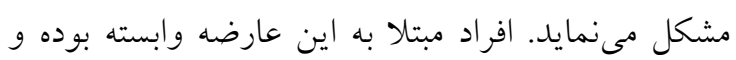

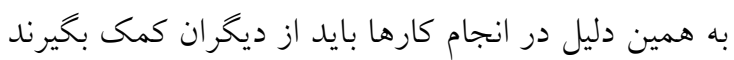

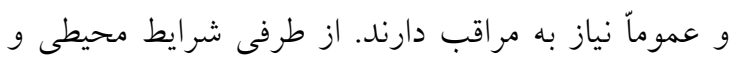

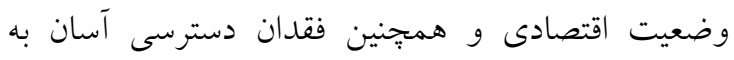
برخى داروها ممكن است در ارزيابى اين افراد از كيفيت

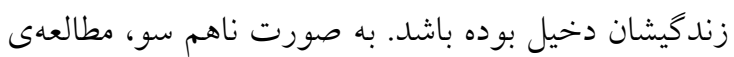
حسينى و همكاران در افراد با ضايعه نخاعى شهر يزد

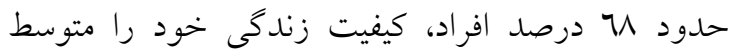
اعلام نمودند (T). هم:جنين در مطالعهى شاهنده و همكاران اعضاى انجمن ضايعات نخاعى شهر تهران را با برسشنامه ى كيفيت زندكى Lancashire و Wisconsin متوسط

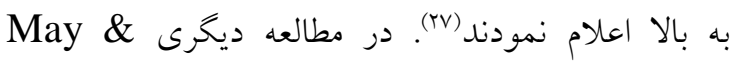
مطالعهى خود را با هدف سنجش كيفيت Warren زندكى افراد مبتلا به آسيب نخاعى انجام دادند كه ميانخين

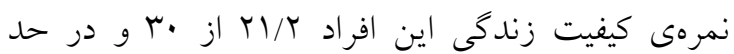

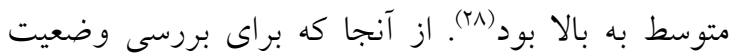

\section{بحث و نتيجه كيرى}

همان طور كه نتايج آزمونهاى آمارى نشان داد داد ميانخين

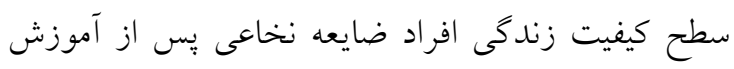

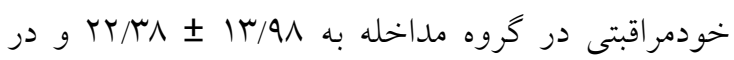

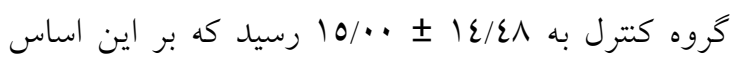

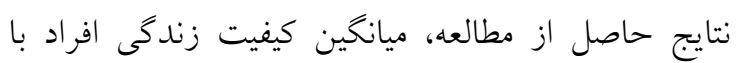

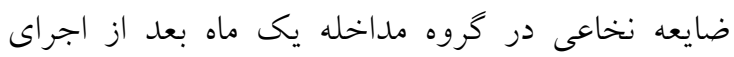

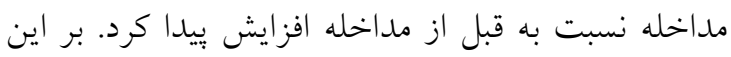

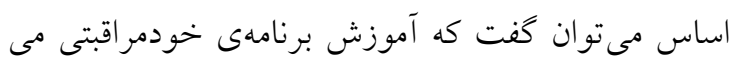

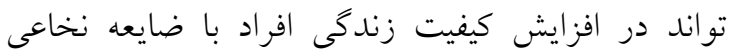
مؤثر باشد. يكى مطالعه در سال Ir IV تحت عنوان كيفيت زندكى افراد با ضايعه نخاعى و نقش ييش بينى كنندهى خلق افسرده توسط موسوى و همكاران انجام كرفت. اين تحقيق يكى مطالعه توصيفى - مقطعى بود. جامعه آمارى شامل تمام افراد در انجمن ضايعات نخاعى استان كيلان بود كه 9V نفر از آنها بر اساس روش نمونه كيرى در دسترس به عنوان نمونه انتخاب شدند. دادههاى مورد نياز با استفاده از يرسشنامه نويسنده اطلاعات جمعيت

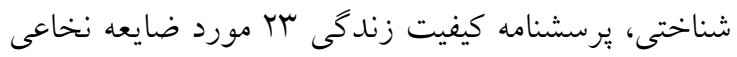

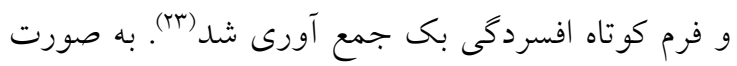

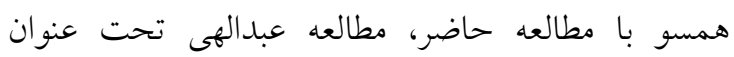
بررسى كيفيت زندگى معلولين ضايعه نخاعى زلزله

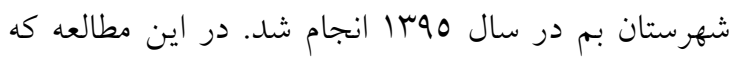

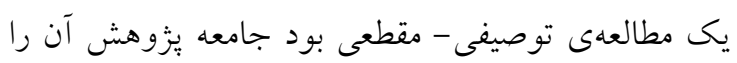

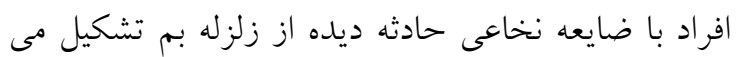

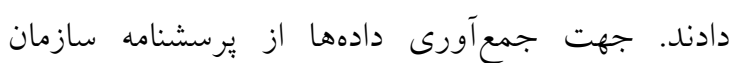
بهداشت جهانى استفاده شد. نتايج نشان داد بين ابعاد

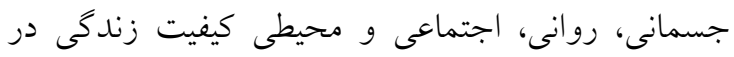
افراد با ضايعه نخاعى حادثه ديده از زلزله بم با اين روتئي مؤلفهها در جامعه نرمال ايرانى اختلاف معنىدارى وجود دارد. در نهايت مشخص شد كه افراد با ضايعه نخاعى فرى فرك زلزله شهرستان بم از كيفيت زندگى مطلوبى برخوردار نبودند (r). ابراهيم زاده و همكاران مطالعهاى را تحت عنوان كيفيت زندگى جانبازان با ضايعه نخاعى جنى 
جشمخيرى در ميزان كيفيت زندكى-افراد با ضايعه نخاعى

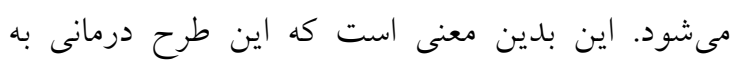

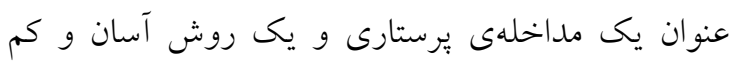
هزينه و در دسترس مىتواند در برنامهى درمانى اين افراد

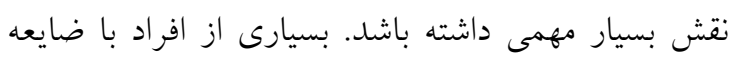

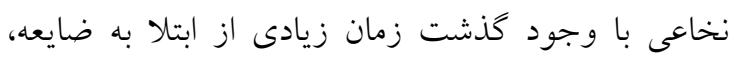

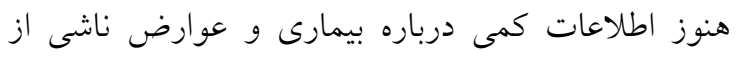

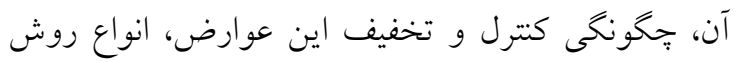

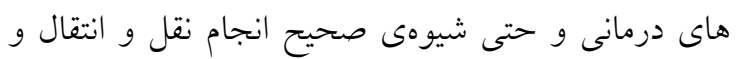

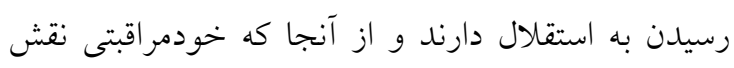
بسيار مهمى در كيفيت زندگى افراد دارند و همبحنين

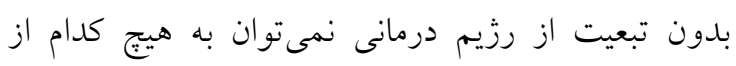

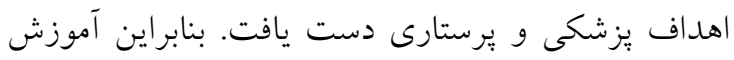

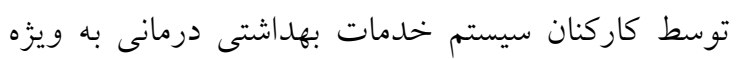

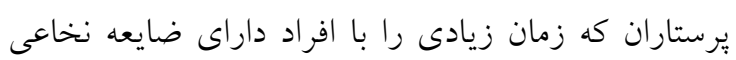

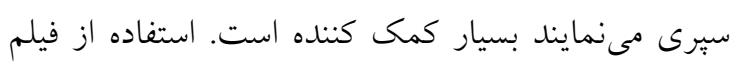

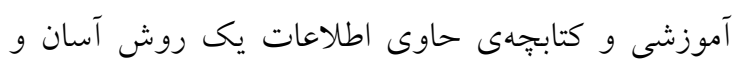

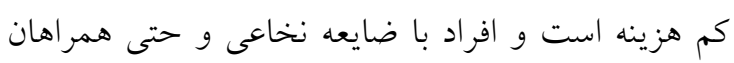

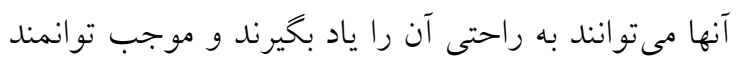

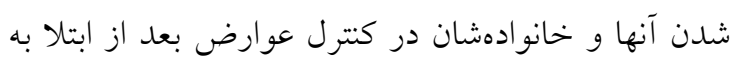

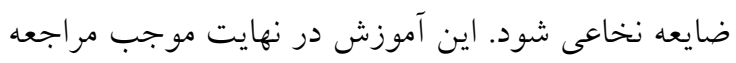

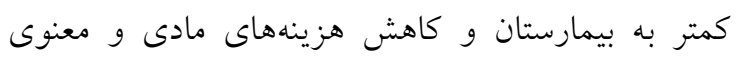

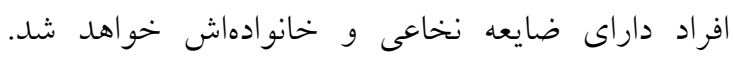
همجنين با توجه به نقش حساس و حياتى يرستاران در

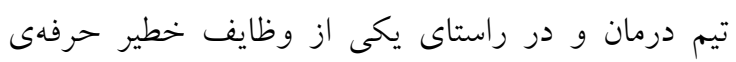

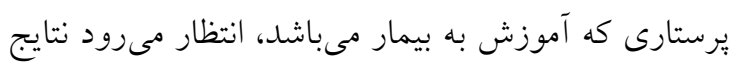

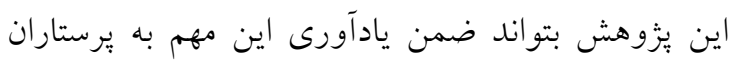

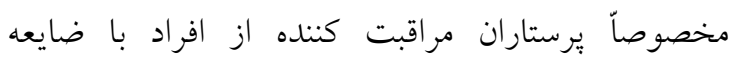

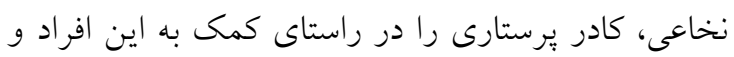

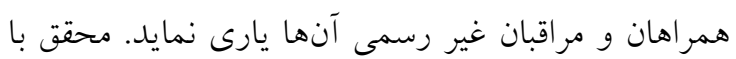

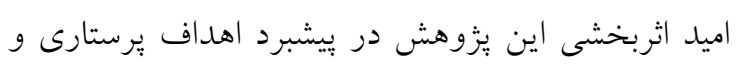

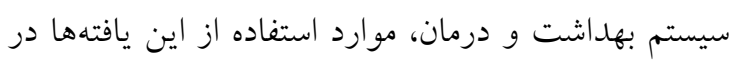

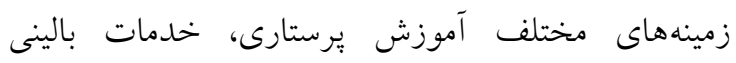
يرستارى و مديريت خدمات برستارى خواهند بوده.
كيفيت زندكى اين افراد يرسشنامهى اختصاصى وجود ندارد و محققان مختلف از ابزارهاى مختلفى مانند كيفيت زئن

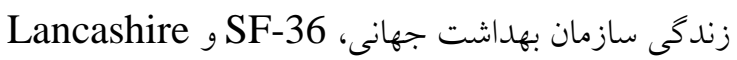
\& Wisconsin اصلى تفاوتها ممكن است به همين علت بركردد. از

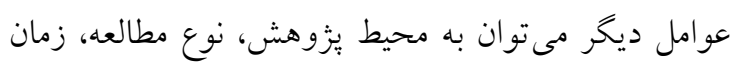
انجام يُزوهش و حتى علت ايجاد ضايعه اشاره نمود. مطالعه ديخرى توسط صدقى گوى آقاج و همكاران تحت

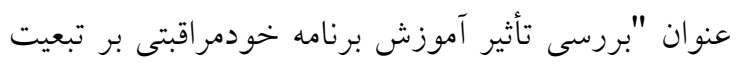

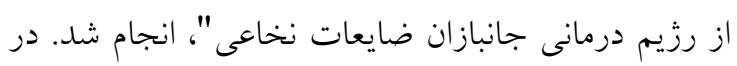
اين مطالعه كه از نوع كارآزمايى بالينى تصادفى بودها

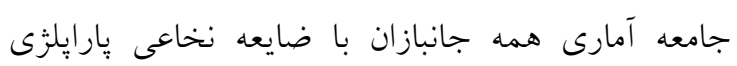

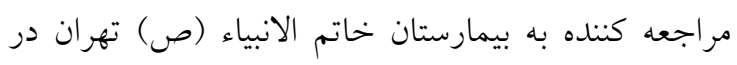

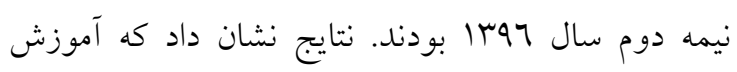

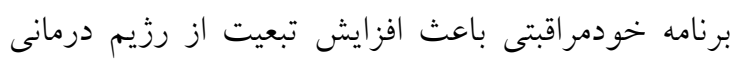

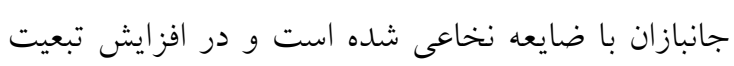

از رزيم درمانى جانبازان ضايعات نخاعى مؤثر است (ج9).

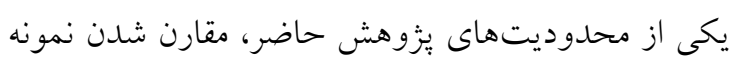

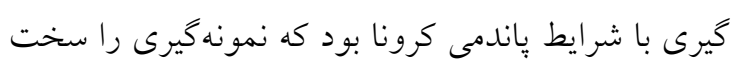

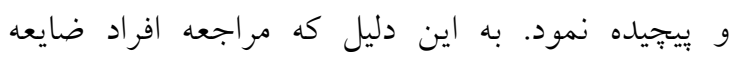

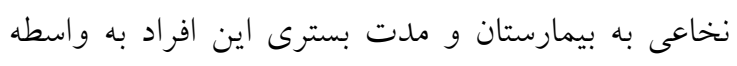

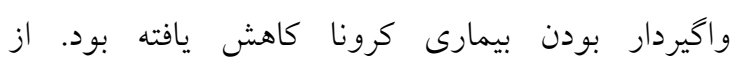

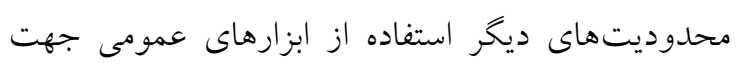

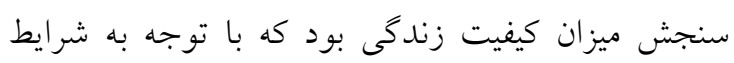
اختصاصى بودن افراد با ضايعات نخاعى احتمالاً نتايج

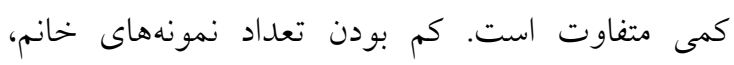
محدوديت ديخر است كه قدرت تعميم به جنس مؤنث را مار

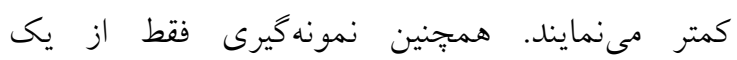
بيمارستان انجام شده است و با توجه به اينكه بيمارستان

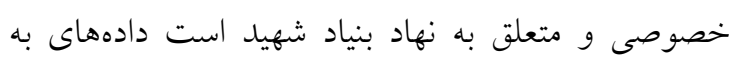
دست آمده فقط به مراجعين همين بيمارستان قابل تعميم مىباشد. يافته هاى يزوهش حاضر نشان داد كه آموزش برنامهى

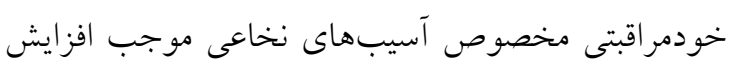




$$
\begin{aligned}
& \text { اين مطالعه بخشى از يايان نامه كارشناسى ارشد يرستارى } \\
& \text { داخلى - جراحى دانشخاه علوم يزشكى ايران مىباشد كه } \\
& \text { در بيمارستان فوق تخصصى خاتم الانبياء (ص) تهران } \\
& \text { انجام شد. از تحصيلات تكميلى دانشخاه و همكارى } \\
& \text { صميمانهى رياست و مديريت محترم بيمارستان، مديريت } \\
& \text { محترم يرستارى و بيماران كرانقدرى كه بدون همكارى } \\
& \text { آنها اين تحقيق ممكن نبود، بىنهايت سياسكزاريم. }
\end{aligned}
$$

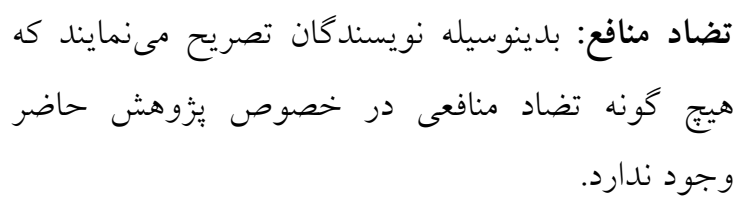

\section{References}

1. Bloom O, Herman PE, Spungen AM. Systemic inflammation in traumatic spinal cord injury. Experimental neurology. 2020;325:113143.

2. Abdolahi M. Evaluation of quality of life in patients with spinal cord injury following the Bam earthquake in 2003. Evaluation. 2016;3(2):1-7. [Persian]

3. Yang B, Zhang F, Cheng F, Ying L, Wang C, Shi K, Wang J, Xia K, Gong Z, Huang X, Yu C. Strategies and prospects of effective neural circuits reconstruction after spinal cord injury. Cell Death \& Disease. 2020;11(6):1-4.

4. Amirian Z, Hemmati MM, Jalali R, Khalkhali H, Salehi S. The Effects of Regular Physical Activity at Home on Patients'quality of Life after Coronary Artery Bypass Surgery. Knowledge \& Health Journal. 2013;8(2):51-6. [Persian]

5. Fatehi F, Kamali M. Perceived experiences of unemployed people with spinal cord injury in the process of returning to work. Journal of research in rehabilitation sciences. 2012;8(2):254-62.

6. Moghaddam M, Davatgaran K, Nazmdeh K. Comprehensive Rihabilitation in spinal cord injury. Department of Rehabilitation. Office for Disability Rehabilitation physical, motor, and sensory. 2007.

7. Sedghi Goyaghaj N, Pishgooie AH, Aliyari S, Zareiyan A. The effect of a self-care training program on adherence to a therapeutic regimen in veterans with spinal cord injury: randomized controlled clinical trial. Journal Mil Med. 2018;20(4):421-30. [Persian]

8. Hasanzadeh Pashang S, Zare H, Alipor A. The efficacy of stress inculation training (SIT) on resilience, anxiety, depression and stress among spinal cord injury (SCI) patients. Journal of Jahrom University of Medical Sciences. 2012;10(3):15-26. [Persian]

9. Craig A, Tran Y, Middleton J. Psychological morbidity and spinal cord injury: a systematic review. Spinal cord. 2009;47(2):108-14.

10. Shokohifar M, Falahzadeh H. Determination quality of lifein patients with type II diabetes andpresentation a structural model. Journal of Mazandaran University of Medical Sciences. 2014;24(116):84-92. [Persian]

11. Seyam S, Heidarnia AR. Quality of life and factors related to it in cardiovascular patients after heart surgery. Journal of Birjand University of Medical Sciences. 2013;19(6):33-41. [Persian]

12. Sahrakhil Lea. The relationship between health literacy, self efficacy and quality of life in cardiovascular patients in selected hospital in qazvin. Tehran: University of Social Welfare and Rehabilitation Sciences. 2017.

13. Eghbali T, Salehi S. The effect of nursing intervention education on self-care behaviors in patients with high blood pressure referred to healthcare centers in Kermanshah province. Iranian Journal of Rehabilitation Research. 2017;4(1):32-7. [Persian]

14. Royani Z, Rayyani M, Behnampour N, Arab M, Goleij J. The effect of empowerment program on empowerment level and self-care self-efficacy of patients on hemodialysis treatment. Iranian journal of nursing and midwifery research. 2013;18(1):84. [Persian] 
15. Gangi S, Peyman N, Meysami BS, Esmaily H. Effect of self-Care training program on Quality of Life and Health literacy in the Patients with Essential Hypertension. Medical Journal Of Mashhad University Of Medical Sciences. 2018;60(6):792-803. [Persian]

16. Sedghigoyaghaj N, Pishgooei A, Alyari S, Zarean A. The effect of self-care program education on Adherence to treatment regimen and self-efficacy in veteran with spinal cord injury in khatamolanbia hospital Tehran: Aja University of medical sciences; 2019. [Persian]

17. Valizadeh S, Soheili A, Moghbeli G, Aliafsari E. Applicablity of orem's self-care model in Iran: an integrated review. Journal Of Urmia Nursing And Midwifery Faculty. 2017;15(4):313-28. [Persian]

18. Noohi E, Abbaszadeh A. Process of Patient Education and Orem, s Self Care Theory, An Integrative Model Curriculum: A Qualitative Study. Journal of Qualitative Research in Health Sciences. 2020;5(4):419-31. [Persian]

19. Richards DA, Hilli A, Pentecost C, Goodwin VA, Frost J. Fundamental nursing care: A systematic review of the evidence on the effect of nursing care interventions for nutrition, elimination, mobility and hygiene. J Clin Nurs. 2018;27(11-12):2179-88.

20. Omidi A, Kazemi N, Khatiban M. Effect of self-care education on self-efficacy in patients with chronic obstructive pulmonary disease in the Educational and Medical Centers of Hamadan University of Medical Sciences. Avicenna Journal of Nursing and Midwifery Care. 2015;23(2):74-84. [Persian]

21. World Health Organization. WHOQOL-BREF: introduction, administration, scoring and generic version of the assessment: field trial version, December 1996. World Health Organization; 1996.

22. Nedjat S, Montazeri A, Holakouie K, Mohammad KA, Majdzadeh R. Quality of life of Tehran's population by WHOQOL-BREF questionnaire in 2005. Hakim Res J. 2007;10(3):1-8. [Persian]

23. Mousavi VA. Quality of life in patients with spinal cord injury: the role of depressed mood. Iranian Journal of Neurosurgery. 2017;2(4):9-14. [Persian]

24. Ebrahimzadeh MH, Soltani MS, Birjandinejad A, Omidi KF, Bozorgnia S. Quality of Life of Veterans With Chronic Spinal Cord Injury and Related Variables. Archives of trauma research. 2014;3(2):1-6. [Persian]

25. Geyh S, Ballert C, Sinnott A, Charlifue S, Catz A, Greve JD, Post MW. Quality of life after spinal cord injury: a comparison across six countries. Spinal Cord. 2013;51(4):322-6.

26. Hosseini H. The survey of quality of life of spinal cord injured people in Yazd in 2014. Military Caring Sciences Journal. 2015;1(2):88-98. [Persian]

27. Shahandeh H, Wameghi R, Hatamizadeh N, Kazemnejad AN. Quality of life among people with spinal cord injuries. Journal of School of Public Health and Institute of Public Health Research. 2005;3(3):1-8. [Persian]

28. May LA, Warren S. Measuring quality of life of persons with spinal cord injury: external and structural validity. Spinal cord. 2002;40(7):341-50.

29. Sedghi Goyaghaj N, Pishgooie AH, Aliyari S, Zareiyan A. The effect of a self-care training program on adherence to a therapeutic regimen in veterans with spinal cord injury: randomized controlled clinical trial. Journal Mil Med. 2018;20(4):421-30. [Persian] 